\title{
Study on Electrophysiological Signal Monitoring of Plant under Stress Based on Integrated Op-Amps and Patch Electrode
}

\author{
Weiming Cai and Qingke Qi \\ School of Information Science and Engineering, Ningbo Institute of Technology, Zhejiang University, Ningbo 315100, China \\ Correspondence should be addressed to Weiming Cai; caiwm@zju.edu.cn
}

Received 11 May 2017; Revised 19 June 2017; Accepted 15 August 2017; Published 10 October 2017

Academic Editor: Jit S. Mandeep

Copyright (C) 2017 Weiming Cai and Qingke Qi. This is an open access article distributed under the Creative Commons Attribution License, which permits unrestricted use, distribution, and reproduction in any medium, provided the original work is properly cited.

\begin{abstract}
Electrophysiological signal in plant is a weak electrical signal, which can fluctuate with the change of environment. An amplification detection system was designed for plant electrical signal acquisition by using integrated op-amps (CA3140, AD620, and INA118), patch electrode, data acquisition card (NI USB-6008), computer, and shielded box. Plant electrical signals were also studied under pressure and flooding stress. The amplification detection system can make nondestructive acquisition for Aquatic Scindapsus and Guaibcn with high precision, high sensitivity, low power consumption, high common mode rejection ratio, and working frequency bandwidth. Stress experiments were conducted through the system; results show that electrical signals were produced in the leaf of Aquatic Scindapsus under the stress of pressure. Electrical signals in the up-leaf surface of Aquatic Scindapsus were stronger than the down-leaf surface. Electrical signals produced in the leaf of Guaibcn were getting stronger when suffering flooding stress. The more the flooding stress was severe, the faster the electrical signal changed, the longer the time required for returning to a stable state was, and the greater the electrical signal got at the stable state was.
\end{abstract}

\section{Introduction}

There are potential changes when life activities occur among living body, biological tissues and organs, and biological cell, which are called electrophysiological signal. The electrophysiological signal is a basic character as well as a behavior in living beings. It is also the general reflection of a series of physical and chemical reactions [1-4]. Some plants would react to external stimulus. For example, the leaves will close with the change of potential when mimosa is stimulated. Stahlberg [5] reviewed the history of electrical signals from the first recordings of action potentials (AP) in sensitive Dionaea and Mimosa plants at the end of the 19th century to their rediscovery in common plants in the 1950s, from the first intracellular recordings of AP in giant algal cells to the identification of the ionic mechanisms by voltage-clamp experiments. Sinyukhin and Britikov [6] who published a thesis about potential build reproductive system in journal called Nature. In recent years, there are a lot of researches about electrical signal in plant all over the world [7-9]. For instance, Ding and Lu's research group recognized plant stress factor by the fuzzy optimal wavelet packet and set up a model based on the environmental factor of electrical signal in plant $[10,11]$. However, the electrical signal is very weak, although magnitudes of electrical reactions can be often about tens $\mathrm{mV}$ (up to $100 \mathrm{mV}$ or more) under environment stimulation; if we take the general detection method to amplify and process the signal, it can be influenced by the zero drift of operational amplifier, the noise, the electromagnetic wave, and the spread of the channel; thus it is difficult for us to obtain authentic signals [12]. Chatterjee et al. [13] provide a platform for realizing a plant signal-based biosensor to classify the environmental stimuli by using raw electrical signals from plants. How to successfully detect which stimuli caused the signal is quite promising because it not only can open the possibility of remotely monitoring the environment of a large geographical area, but also can help in taking timely preventive measures for natural or man-made disasters. However, at present, it is difficult to find an instrument and equipment which is specifically applied to detect the electrophysiological signal in plant. And it is not conducive to satisfy models to guide agricultural production. It is of great 
significance for developing professional plant electrical signal equipment, setting up a prediction model based on the electrical signal in plant, and promoting the application of plant electrical signal in agriculture to find ways to detect electrical signal in plant.

Besides, China always suffers from serious flooding. About two-thirds of the land area suffers different degrees of flooding [14]. The waterlogging stress is a kind of water stress, and the water stress includes drought stress (moisture loss) and waterlogging stress (flood). The damage caused by flood is called waterlogging injury. Waterlogging stress is very harmful to plant growth. There is a limit to the demand for water plants; too less or too much water will be harmful to plant growth. Water deficit can cause drought, and waterlogging stress can cause the plant roots decay. At present, people have partly understood the mechanism of plants' response to the flooding stress but there is still a need for more study to be done $[15,16]$.

Therefore, a method for detecting the physiological signals of plants is proposed in the paper. Through studied changes in the electrophysiological signals of stress on Aquatic Scindapsus and Guaibcn, the detecting system will be tested on whether stable plant electrical signal can be collected correctly; moreover, stress experiments were conducted through the detecting system to find the rule of waterlogging stress influence on the plant electrical signals.

\section{Principles and Methods}

2.1. Composition of the Detection System of Electrical Physiological Signal in Plant. As shown in Figure 1, the detection system consists of electrode, amplifying circuit, data acquisition card, shield, and so on. The graphite patch electrode was used to measure the electrical signals on the surface of the plant. The amplifying circuit consists of three integrated operational amplifiers (CA3140, AD620, and INA118), two integrated voltage stabilizing circuits (CW7805, CW7905), and one data acquisition card (NI USB-6008). The shield was made of aluminum foil.

2.2. The Design Principle of Amplifying Circuit. Figures 2 and 3 are the amplifying circuit principle diagram of the electrophysiological signal in plant and PCB plate-making figure, respectively.

As shown in Figures 2 and 3, in view of the uncertainty of the size of plant resistance and the frequency interference caused by the ends of the amplifying, we should add two high input impedance circuit operational amplifiers (CA3140) and form a depth series voltage negative feedback in order to get less interference, and it can also form a differential circuit with instrumentation amplifier (AD620). Since the common mode voltage output voltage and drift which are caused by CA3140 can counteract each other, the amplifying circuit has advantages of small voltage output drift and strong common mode rejection capability.

The signal is amplified by AD620; however, if the signal is just amplified by AD620, circuit might burn out which is caused by the sudden increase of signal. So we used INA118 which contains input protection circuit to amplify the signal secondly. If the inputs overload, protection circuit can ensure the safety of the follow-up circuit by limiting the input current in $1.5 \mathrm{~mA}$ to $5 \mathrm{~mA}$. INA118 has some advantages like high precision, low consumption, high membrane rejection ratio, wide working frequency band, and so on. It is suitable for the amplification of small signals. Its gain formula is

$$
G=49.4 \frac{K}{R}+1
$$

In Figure 2, the external resistor of CA3140 is $10 \mathrm{kohms}$ of the potentiometer; the first stage for amplification circuit is AD620; the external resistor of AD620 is a $200 \mathrm{ohms}$ of the potentiometer. After adjusting potentiometer to $167 \mathrm{ohms}$, magnification of 300 times was obtained. The second stage for amplification circuit is INA118; the external resistor of INA118 is $2 \mathrm{kohms}$ of the potentiometer. After adjusting potentiometer to $2 \mathrm{kohms}$, the magnification of 20 times was obtained, and the amplifying circuit can magnify the electrical signals 6000 times totally.

\subsection{Design of Experiments on Plant Electrical Signal Detection} under Stress. In order to examine whether the amplification detection system of electrophysiological signal in plant can gather reliable electrical signal and study the changing rules of the electrophysiological signals in plants under stress, based on the Aquatic Scindapsus and Guaibcn as the research object, the following tests were designed.

(a) Electrical Signal Detection of Aquatic Scindapsus Leaf Surface under Compressive Stress. Aquatic Scindapsus that grows well was chosen in the study. Electrical signals on the Aquatic Scindapsus surface were detected when the leaves of Aquatic Scindapsus were clamped by clip. When Aquatic Scindapsus is under pressure, the potential voltage change of electrical signals on the up-leaf and down-leaf surface of Aquatic Scindapsus was measured. Specific experimental steps are as follows.

(1) Attach graphite patch electrode A (measurement electrode) on the up-leaf or down-leaf surface of one leaf of Aquatic Scindapsus and graphite patch electrode B (reference electrode) posted on the Aquatic Scindapsus stem which is connected with the leaf.

(2) After equipping with batteries and turning on the circuit, let it stand for 40 minutes until the numerical digit of voltage becomes stable; then save the voltage data in the computer.

(3) Clamp the leaves of Aquatic Scindapsus by clip, record the instantaneous potential change, and observe the potential changes. Then remove the clamp and repeat parallel experiments 10 times.

(4) Remove graphite patch electrode A, attach to the Aquatic Scindapsus under the leaf (the same as the measuring objects before, detecting the same leaf; the only difference was that one is to detect the up-leaf surface but the other is to detect the down-leaf surface), and attach a graphite patch electrode on the Aquatic Scindapsus stem which is connected with the leaf. 


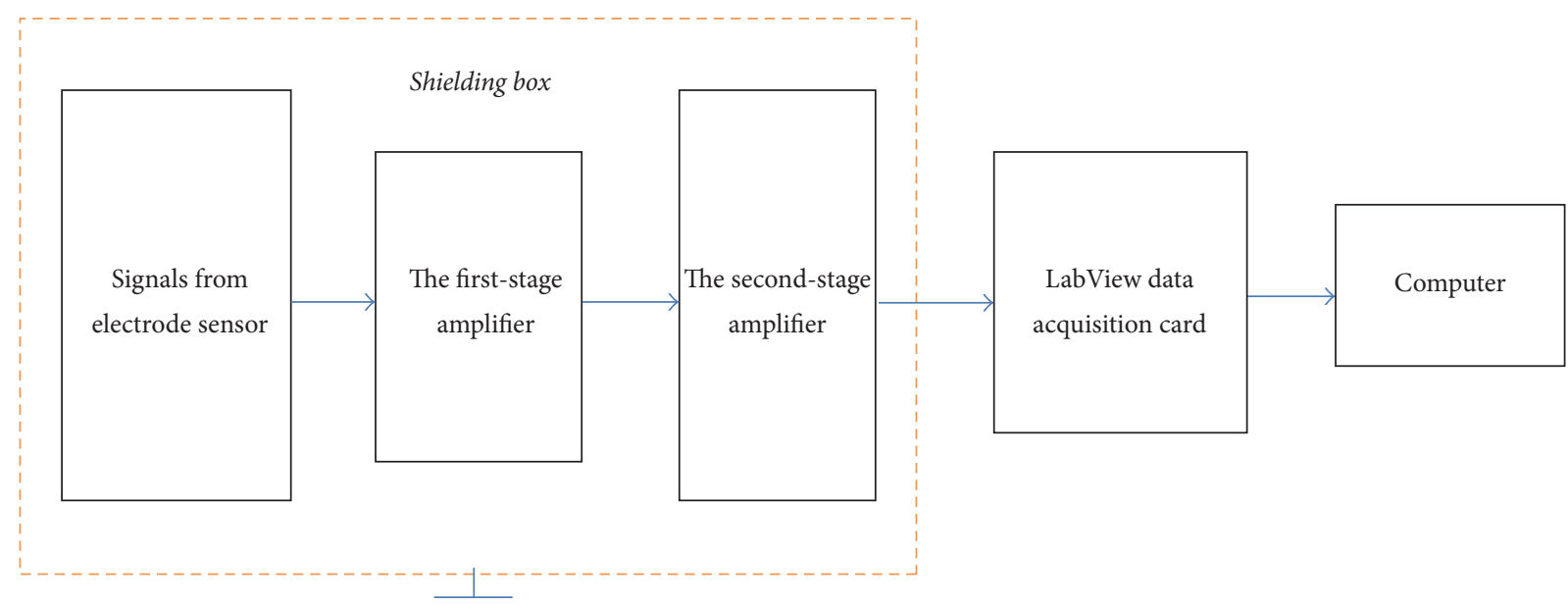

FIGURE 1: Structure diagram of the electrical signals detection system for plant.

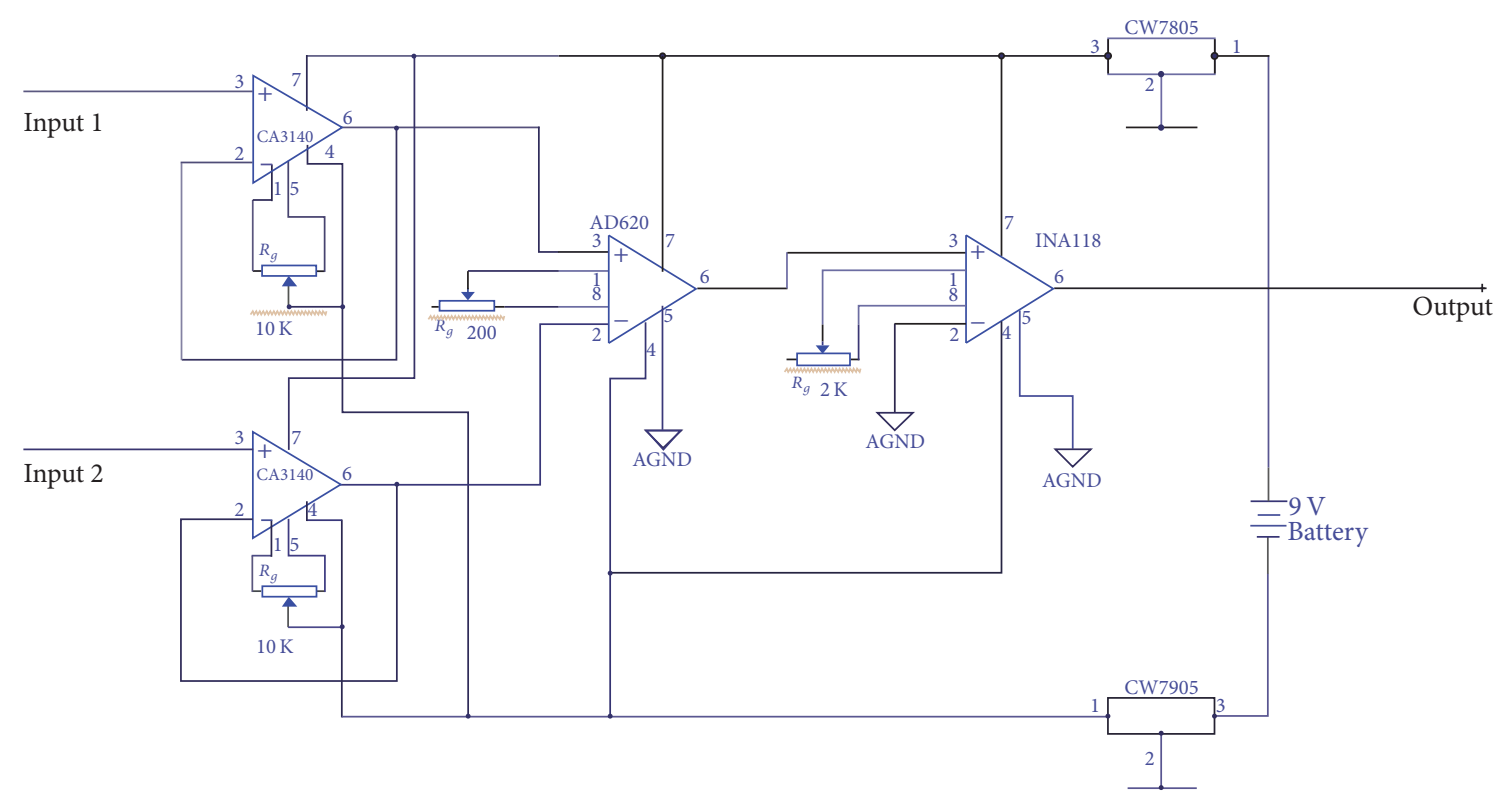

FIGURE 2: Schematic diagram of electrical signals amplifying circuit for plant.

(5) After equipping with batteries and turning on the circuit again, let it stand for 40 minutes until the numerical digit of voltage becomes stable; then save the voltage data in the computer.

(6) Clamp the leaves of Aquatic Scindapsus by clip, and record the instantaneous potential change as well as observing the potential changes. Then remove the clamp, to repeat parallel experiments 10 times; compare the potential difference between up-leaf surface and down-leaf surface.

(b) Electrical Signal Detection of Guaibcn under Waterlogging Stress. Guaibcn that grows well was chosen in the study. By watering Guaibcn continuously (simulating the rainy day) or applying one-time watering (simulating rainstorm), then, observe the change of the electrical signal of Guaibcn.
In order to study the Guaibcn electrical signals in rainy season affected by the persistent plum rains, the Guaibcn was watered persistently with $50 \mathrm{ml}$ each time, then observing the change of the electrical signal of Guaibcn. Specific experiment steps are as follows.

(1) Attach graphite patch electrode A (measurement electrode) on the down-leaf surface of one leaf of Guaibcn and the graphite patch electrode $B$ (reference electrode) posted on the Guaibcn stem which is connected with the leaf.

(2) After equipping with batteries and turning on the circuit, let it stand for 40 minutes until the numerical digit of voltage becomes stable, then saving the voltage data in the computer.

(3) Water the Guaibcn, observe the change of the electrical signal of Guaibcn, and record the voltage value every 30 


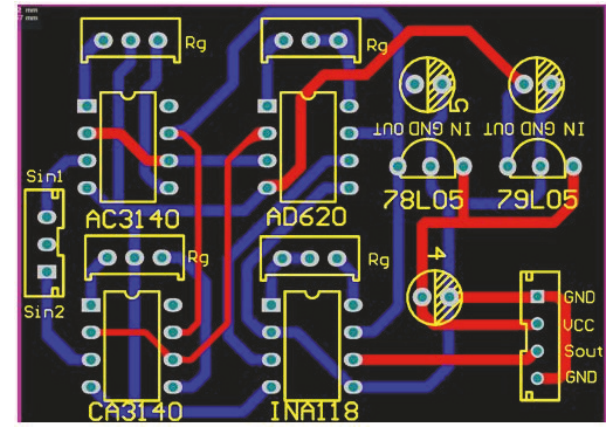

Figure 3: Printed circuit board diagram of electrical signals amplifying circuit for plant.

seconds. Water the Guaibcn by $50 \mathrm{ml}$ water again after it keeps stable (the time points of watering are $6 \mathrm{~min}, 20 \mathrm{~min}, 25 \mathrm{~min}$, and $30 \mathrm{~min}$ ).

In order to observe the change of the electrical signal of Guaibcn when rainstorm occurs, add $200 \mathrm{ml}$ water into the culture soil of the Guaibcn and then save the voltage data every 30 seconds in the computer. Specific experiment steps are as follows.

(1) Attach graphite patch electrode A (measurement electrode) on the down-leaf surface of one leaf of Guaibcn and graphite patch electrode B (reference electrode) posted on the Guaibcn stem which is connected with the leaf.

(2) After equipping with batteries and turning on the circuit, let it stand for 40 minutes until the numerical digit of voltage becomes stable and then save the voltage data in the computer.

(3) Add $200 \mathrm{ml}$ water into the culture soil of the Guaibcn and then save the voltage data every 30 seconds in the computer.

(c) Statistical Analysis. There are ten repetitions in the study. Data were analyzed using an analysis of variance (ANOVA) multiple comparison (single factor). The differences between the experiment and control were tested by the method. Stress effects were considered to be significant at $P<0.05$.

\section{Results and Discussion}

3.1. Aquatic Scindapsus Electrical Signal before and after the Pressure of Leaves. Figures 4 and 5 showed the comparison chart about voltage values (the real magnitude is 1/6000 times the magnitude after amplification as shown in the figures) of electrical signals in the up-leaf surface of Aquatic Scindapsus before and after the pressure, respectively.

In Figure 4, the maximum change of electrical signal on the leaf is $0.0033 \mathrm{~V}$, and the minimum is $0.000 \mathrm{~V}$, the median is $0.0017 \mathrm{~V}$, the average is $0.0006 \mathrm{~V}$, the standard deviation is 0.001092 , and the coefficient of dispersion is 1.82. In Figure 5, the maximum number of the changes of electrical signal under leaf is $0.0047 \mathrm{~V}$, the minimum is $0.0010 \mathrm{~V}$, the median is $0.0029 \mathrm{~V}$, the average is $0.0032 \mathrm{~V}$, the standard deviation is 0.001361 , and the coefficient of dispersion is 0.42 . From Figures 4 and 5, we can find that the signal of up-leaf surface

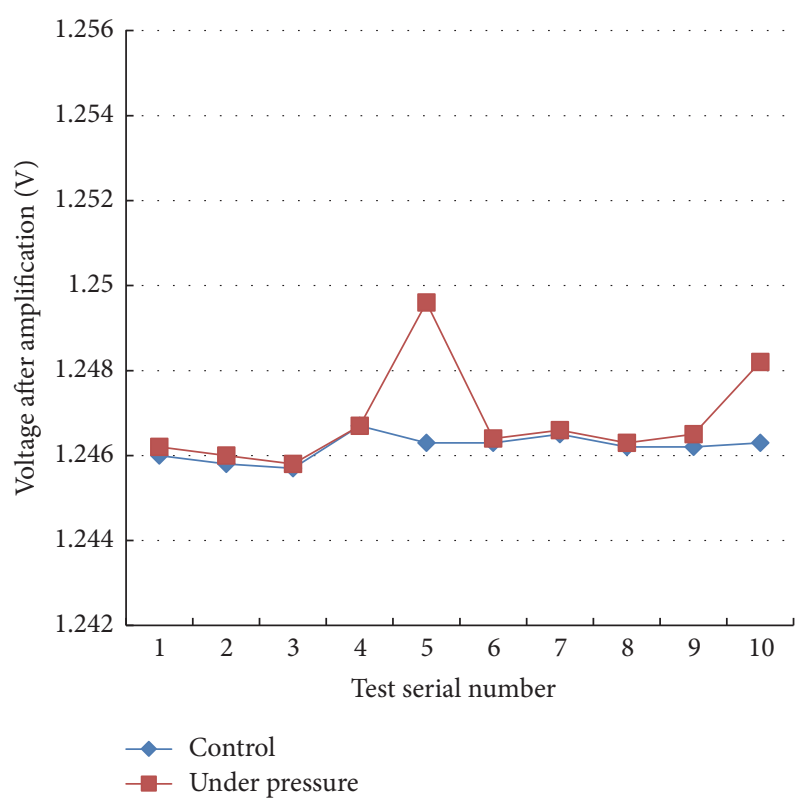

Figure 4: Voltage values of electrical signals in the up-leaf surface of Aquatic Scindapsus.

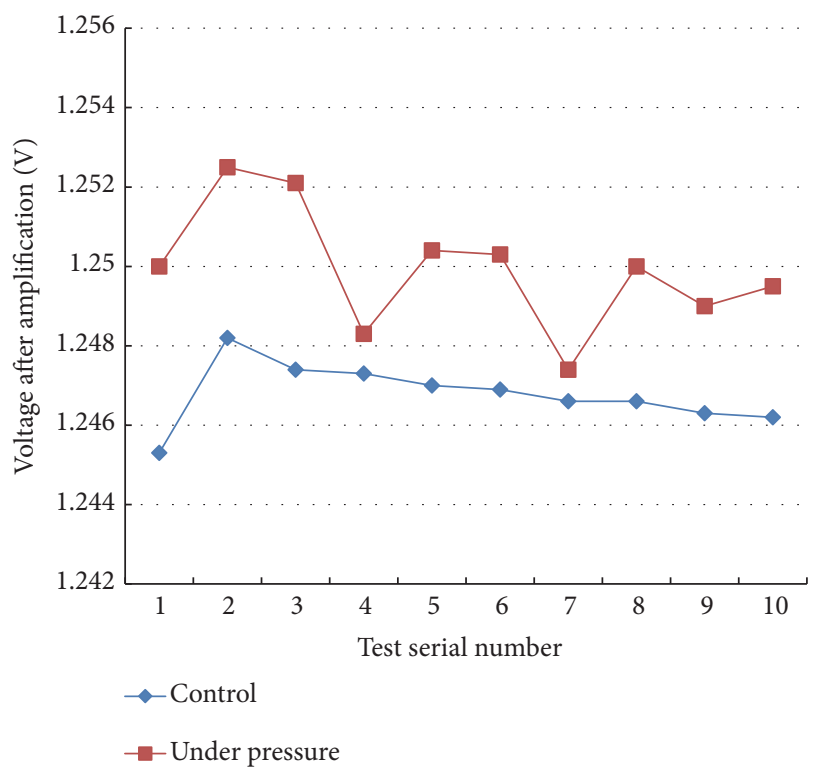

FIGURE 5: Voltage values of electrical signals in the down-leaf surface of Aquatic Scindapsus.

does not change obviously before and after the clamping; only two sets of data have large potential change, but the changes of down-leaf surface are obvious; there are 8 sets of data that have obvious potential rise phenomenon. As we know, many plants can efficiently produce electric signals in the form of action potentials (AP) and variation potentials (VP) and the long-distance propagation of these signals proceeds in the vascular bundles [5]. Therefore, the experimental results indicated that the changes of down-leaf surface are more obvious than the up-leaf surface, probably because the leaf 
vein (as the vascular bundles) is more near to the down-leaf of down-leaf surface.

Since there are two sets of data values (5 and 10) deviating from the value of the other eight sets of data, we suppose the two sets of data as the unreliable data caused by interference. After removing the two unreliable data, we find that the maximum number of the changes of electrical signal on leaf is $0.0003 \mathrm{~V}$, the minimum is $0.0000 \mathrm{~V}$, the median is $0.0002 \mathrm{~V}$, the average is $0.00012 \mathrm{~V}$, the standard deviation is $8.57 \mathrm{E}-05$, and the coefficient of dispersion is 0.623 . After removing those two groups of data, the discrete coefficient decreased significantly.

By analysis and comparison of the data above, we found that the electrical signal of Aquatic Scindapsus will change and amplitude will increase under the action of external pressure. After the signal is amplified by amplification, the potential of the up-leaf surface increases in average by $0.00006 \mathrm{~V}$ and the down-leaf surface increase in average by $0.0032 \mathrm{~V}$. The growth rate of down-leaf surface is greater than the upleaf surface. The reason why the electrical signal in plant falls fast after removing the pressure might relate to the production mechanism of the electrical signal in plant and the mechanism of conduction [17].

\subsection{Changes of the Electrical Signal of Guaibcn under Waterlogging Stress}

3.2.1. Changes of the Electrical Signal of Guaibcn under OneTime Flooding. Figure 6 is the change of the electrical signal of Guaibcn under one-time water flooding.

In Figure 6, the time we started to add water is on the red arrow point ( 0 moment on $x$-axis). As shown in Figure 6, before adding water, curve is flat and fluctuates in a small scope. After we added $200 \mathrm{ml}$ water, curve rose gradually and achieved the highest point about 28 minutes later, and then the curve declined and returned back to the potential before watering. After we added a lot of water, the potential rises quickly, and the rate of change was in the positive; then the rate of change declined, until becoming in the negative. When the potential almost returns to the data which is the data before we added water, the fluctuation of the rate of change was near zero. The result is similar to the avocado tree's action with irrigation provided by Gurovich and Hermosilla [18].

Flooding can result in an anaerobic situation in the plant root system that induces $\mathrm{pH}$ changes in the apoplast and symplast. Therefore, electrical potential increased during flooding is probably because of $\mathrm{pH}$ changes in the apoplast and symplast.

\subsubsection{The Change of the Electrical Signal of Guaibon under} Continuous Adding of Water. Figure 7 showed the change of the electrical signal of Guaibcn under continuous water flooding.

In Figure 7, the time we started to add water is on the red arrow point ( 0 moment on $x$-axis). The potentials of stem and leaf rise slowly after watering the first $50 \mathrm{ml}$ water. After 2 minutes, the potential rises quickly. Six minutes later, the electrical signal gradually stabilized. After watering the second $50 \mathrm{ml}$, the potentials of stem and leaf rise immediately, and three minutes later, the electrical signal gradually stabilized. After watering the third and fourth $50 \mathrm{ml}$ water, the potentials of stem and leaf rise immediately. But the rise degree was less than the previous two, and the fourth was also less than the third. The electrical signal gradually stabilized two minutes later.

Several physiological mechanisms that explain electric responses to irrigation have been postulated. Action potential (AP) and variation potential (VP) lead to a physiological reaction by informing distant cells about local stimuli [19]. Additional signalling mechanisms in plants have been reported, including modifications of cytoplasmatic $\mathrm{pH}[20,21]$.

The above two kinds of experiments of Guaibon were carried out under the condition of flooding stress. The first experiment added water four times, and $50 \mathrm{ml}$ water was added each time; the electrical signal of Guaibon changes obviously after we added the first $50 \mathrm{ml}$ water for 3 minutes. The second experiment added $200 \mathrm{ml}$ water one time, and the electrical signal changes immediately after adding water. Through the above analysis, we found the following:

(1) The main phenomenon of the change of Guaibcn under water flooding was the amplitude of electrical signal increases.

(2) The change of electrical signal of Guaibcn relates to the amount of water, the more severe the water flooding is, the quicker the electrical signal changes, the larger the amount of change is, and the longer the time required for returning to a stable state is.

(3) The electrical signal produced under the water flooding can restore its original state as long as the water is in a certain range.

\section{Conclusions}

(1) Patch electrode and integrated operational amplifiers (CA3140, AD620, and INA118) were used to design an amplifier circuit with advantage of high precision, high sensitivity, low power consumption, high membrane rejection ratio, and wide working frequency band. The amplification detection system can make nondestructive acquisition for Aquatic Scindapsus and Guaibcn.

(2) According to the experiment results, the electrophysiological signal detection system can collect stable electrical signals and satisfy the need of analysis of the electrophysiological signal based on the combination of the patch electrode and amplifying circuit (consisting of CA3140, AD620, INA118, CW7805, and CW7905).

(3) According to the study about the change of electrical signal of Aquatic Scindapsus under compressive stress, we found that Aquatic Scindapsus could generate the electrical signal under compressive stress, and the change of down-leaf is greater than the up-leaf.

(4) According to the study about the change of electrical signal of Guaibcn under purpose of stress, we found that the electrical signal of Guaibcn would rise under waterlogging stress, and the change degree relates to the amount of water; the more severe the waterlogging stress is, the quicker the electrical signal changes, the larger the amount of change is, and the longer the time required for returning to a stable state. 


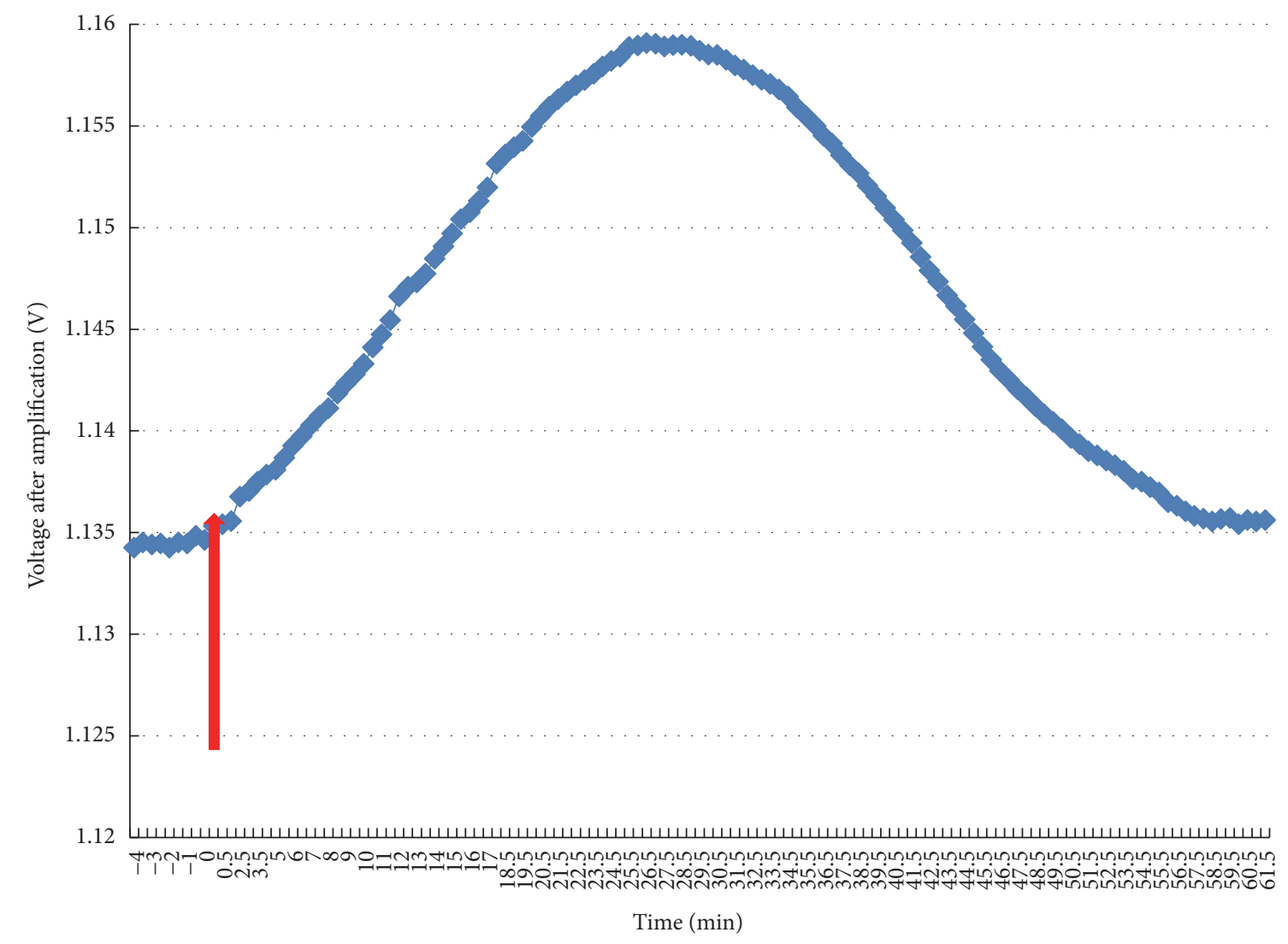

FIgURE 6: Changes of electrical signals for Guaibcn under one-time water flooding.

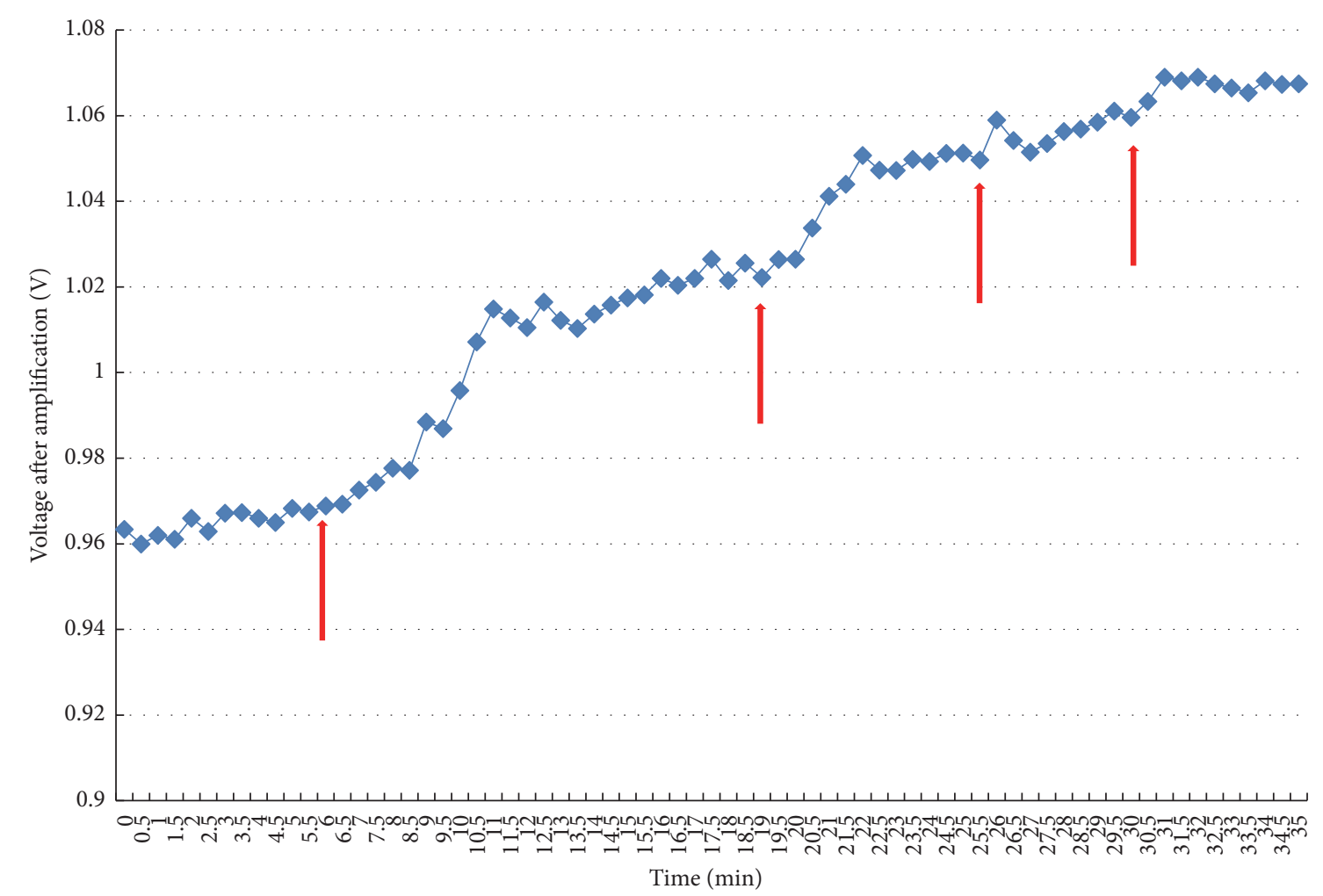

Figure 7: Changes of electrical signals for Guaibcn under continuous water flooding. 
The electrical signal produced under the water flooding can restore its original state as long as the water is in a certain range.

The relationship between the plant physiological parameters and the electrical signals is very complex. The results of the study provided a method for developing electrophysiological signal monitoring device of plant and a reference for studying the change rule of the plant electrophysiological signals under stress.

\section{Conflicts of Interest}

The authors declare that they have no conflicts of interest regarding this work.

\section{Acknowledgments}

The authors acknowledge that the research was supported by the General Scientific Research Project of Zhejiang Education Department (Y201534782), Ningbo Natural Science Foundation (2014A610155), Ningbo Enriching Program of Science and Technology (2015C10014), Research Project of Public Welfare Technology Application in Zhejiang Province (2016C32106), the Humanities and Social Sciences Foundation of the Ministry of Education (16YJCZH112), and College Talent Funds of Ningbo Institute of Technology, Zhejiang University (1141257G1402).

\section{References}

[1] Y.-C. Wang, P. Li, and D.-F. Chi, "Electrophysiological and behavioral responses of Tenebrio molitor L. to fourteen kinds of plant volatiles," Journal of Asia-Pacific Entomology, vol. 19, no. 2, pp. 261-267, 2016.

[2] E. Michard, M. M. Wudick, M. A. Lizzio, C. O. Ramírez, C. Campos, and J. A. Feijó, "Plant glutamate receptors: electrophysiological characterization and evolutionary perspectives," Biophysical Journal, vol. 110, no. 3, pp. 404-405, 2016.

[3] X. Xu, X. Cai, L. Bian, Z. Luo, Z. Xin, and Z. Chen, "Electrophysiological and behavioral responses of Chrysopa phyllochroma (Neuroptera: Chrysopidae) to plant volatiles," Environmental Entomology, vol. 44, no. 5, pp. 1425-1433, 2015.

[4] M. R. Zimmermann, A. Mithöfer, T. Will, H. H. Felle, and A. C. U. Furch, "Herbivore-triggered electrophysiological reactions: Candidates for systemic signals in higher plants and the challenge of their identification," Plant Physiology, vol. 170, no. 4, pp. 2407-2419, 2016.

[5] R. Stahlberg, "Historical overview on plant neurobiology," Plant Signaling and Behavior, vol. 1, no. 1, pp. 6-8, 2006.

[6] A. M. Sinyukhin and E. A. Britikov, "Action potentials in the reproductive system of plants," Nature, vol. 215, no. 5107, pp. 1278-1280, 1967.

[7] V. Sukhov, "Electrical signals as mechanism of photosynthesis regulation in plants," Photosynthesis Research, vol. 130, no. 1-3, pp. 373-387, 2016.

[8] V. A. Vodeneev, L. A. Katicheva, and V. S. Sukhov, "Electrical signals in higher plants: mechanisms of generation and propagation," Biophysics, vol. 61, no. 3, pp. 505-512, 2016.

[9] H. Y. Weng, D. P. Ye, J. G. Zheng, H. Y. Li, X. Liang, and S. H. Chen, "Research on characteristics of plant electrical signal under high voltage pulse stimulation," Applied Mechanics and Materials, vol. 513-517, pp. 3122-3125, 2014.

[10] H. Lu, X. Jing, W. M. Ding, H. M. Yu, and W. L. Ling, "Plant stress recognition based on fuzzy-rule using optimal wavelet packet," Transactions of the Chinese Society for Agricultural Machinery, vol. 43, no. 12, pp. 217-221, 2012 (Chinese).

[11] J. X. Lu, H. M. Yu, and S. J. Chen, "Environment factor prediction models based on plant electrical signals," Transactions of the Chinese Society for Agricultural Machinery, vol. 44, no. 11, pp. 229-233, 2013 (Chinese).

[12] H. Wu, L. G. Tian, S. Hu, Z. L. Chen, and M. Li, "Detection system on weak electrical signal in plants," Applied Mechanics and Materials, vol. 427-429, pp. 2037-2040, 2013.

[13] S. K. Chatterjee, S. Das, K. Maharatna et al., "Exploring strategies for classification of external stimuli using statistical features of the plant electrical response," Journal of the Royal Society Interface, vol. 12, no. 104, pp. 1-13, 2015.

[14] Y. Lou, Y. Pan, C. Gao, M. Jiang, X. Lu, and Y. J. Xu, "Response of plant height, species richness and aboveground biomass to flooding gradient along vegetation zones in floodplain wetlands, Northeast China," PLoS ONE, vol. 11, no. 4, Article ID e0153972, 2016.

[15] S. Orchard, R. J. Standish, D. Nicol, V. V. S. R. Gupta, and M. H. Ryan, "The response of fine root endophyte (Glomus tenue) to waterlogging is dependent on host plant species and soil type," Plant and Soil, vol. 403, no. 1-2, pp. 305-315, 2016.

[16] B. Xu, Y. Cheng, X. Zou, and X. Zhang, "Ethanol content in plants of Brassica napus L. correlated with waterlogging tolerance index and regulated by lactate dehydrogenase and citrate synthase," Acta Physiologiae Plantarum, vol. 38, no. 3, article 81, pp. 1-9, 2016.

[17] E. Davies, "New functions for electrical signals in plants," New Phytologist, vol. 161, no. 3, pp. 607-610, 2004.

[18] L. A. Gurovich and P. Hermosilla, "Electric signalling in fruit trees in response to water applications and light-darkness conditions," Journal of Plant Physiology, vol. 166, no. 3, pp. 290300, 2009.

[19] J. Fromm and S. Lautner, "Electrical signals and their physiological significance in plants," Plant, Cell \& Environment, vol. 30, no. 3, pp. 249-257, 2007.

[20] H. H. Felle, "pH: Signal and messenger in plant cells," Plant Biology, vol. 3, no. 6, pp. 577-591, 2001.

[21] V. Gloser, H. Korovetska, A. I. Martín-Vertedor et al., “The dynamics of xylem sap $\mathrm{pH}$ under drought: a universal response in herbs?" Plant and Soil, vol. 409, no. 1-2, pp. 259-272, 2016. 


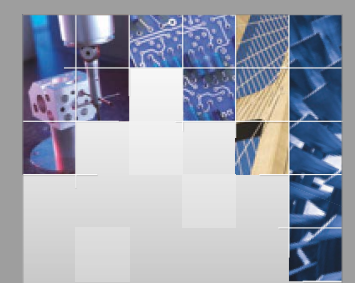

\section{Enfincering}
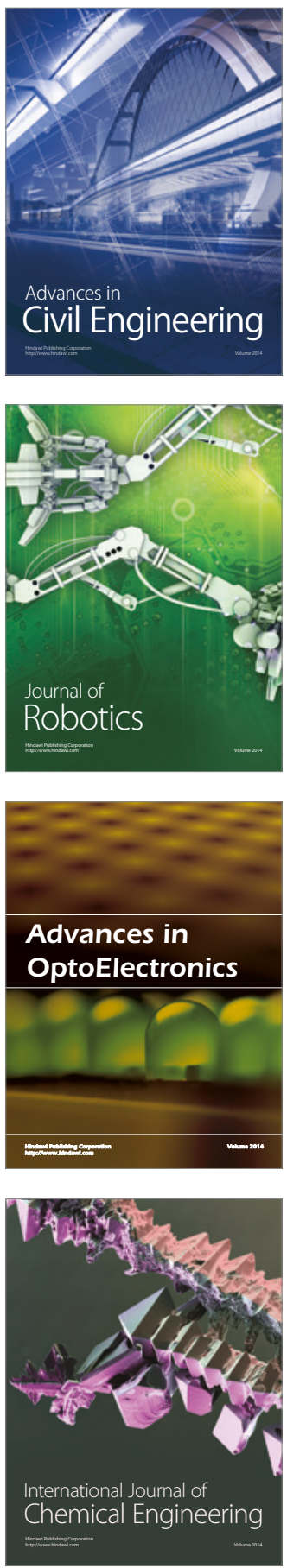

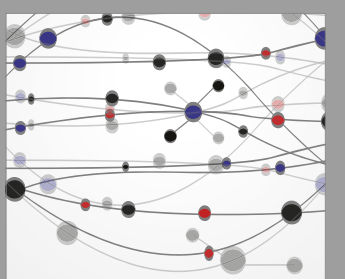

The Scientific World Journal

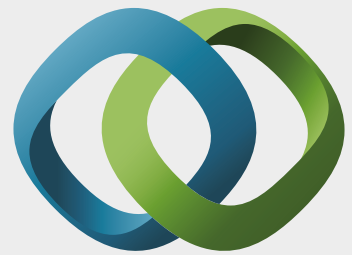

\section{Hindawi}

Submit your manuscripts at

https://www.hindawi.com
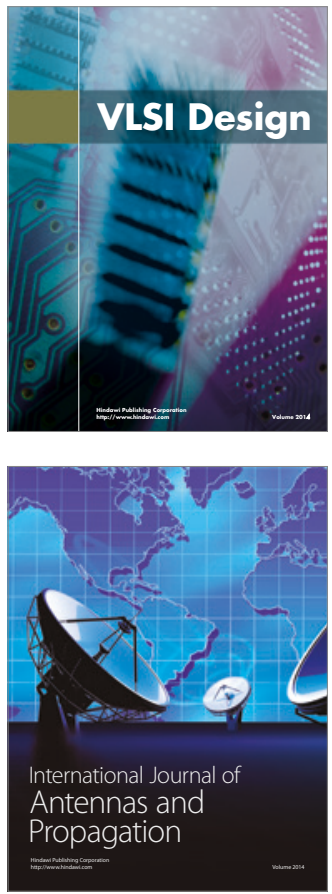

\section{Rotating}

Machinery
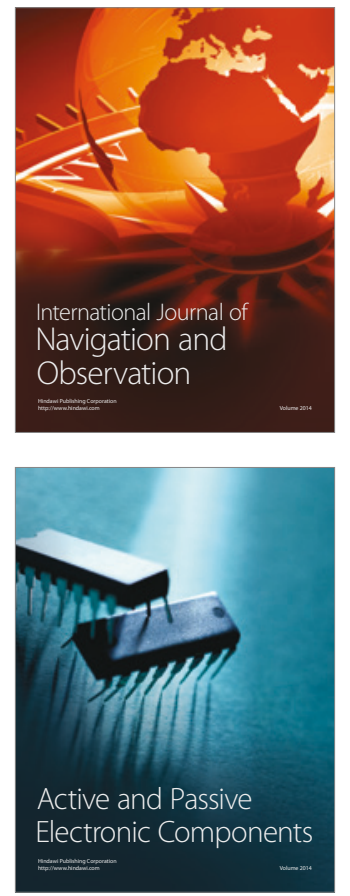
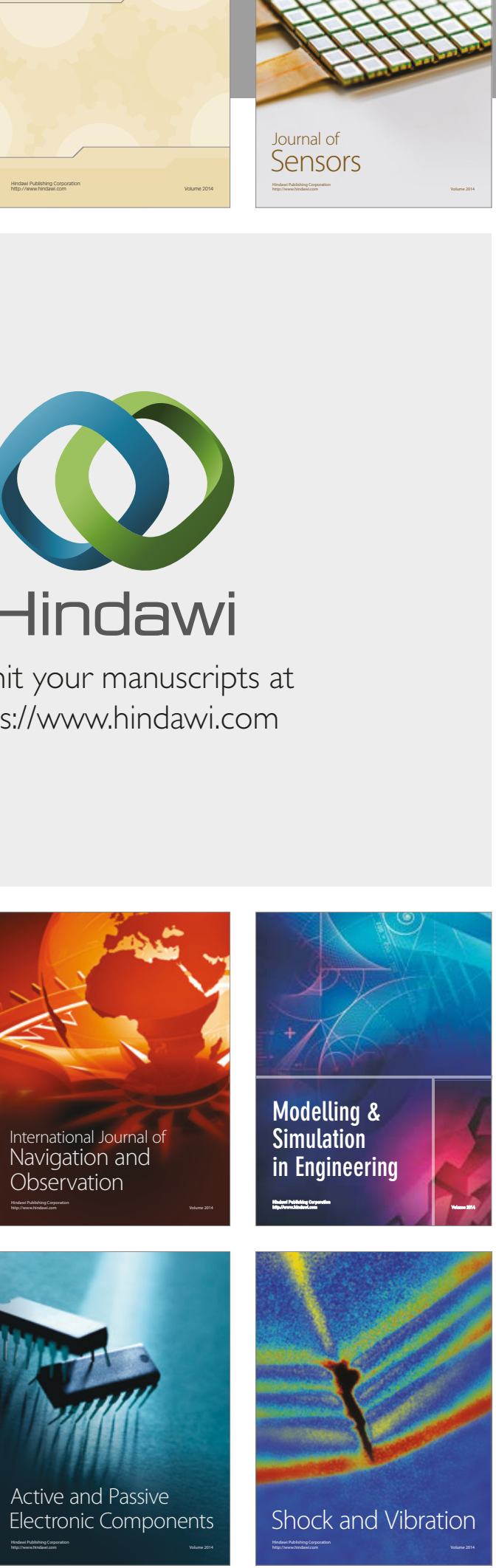
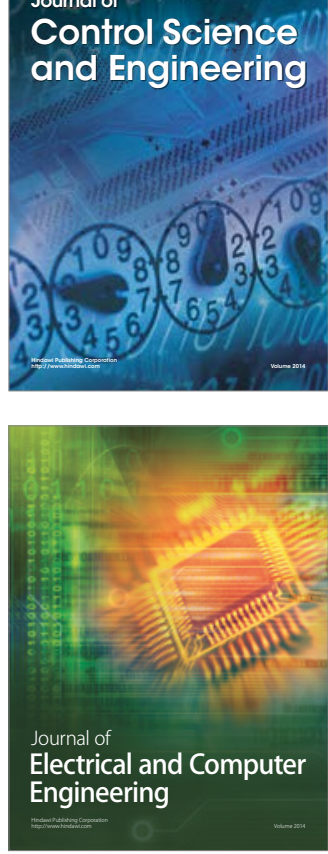

Distributed

Journal of

Control Science

and Engineering
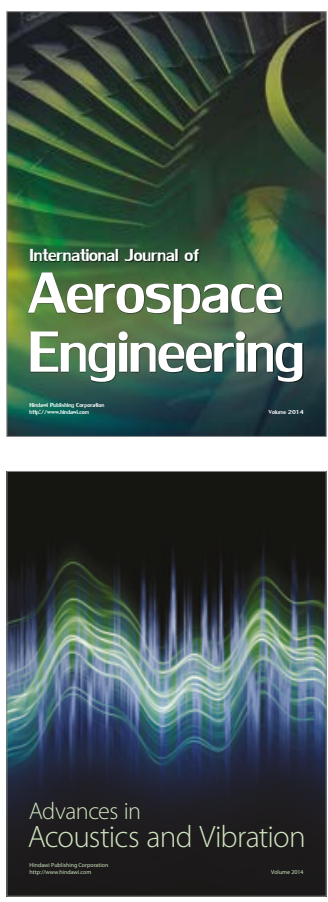

Sensor Networks 